\title{
Case reports of melamine-induced pathology in penaeid shrimp fed adulterated feeds
}

\author{
Donald V. Lightner ${ }^{1, *}$, Carlos R. Pantoja ${ }^{1}$, Rita M. Redman ${ }^{1}$, Kenneth W. Hasson ${ }^{2}$, \\ Jayagopal Pozoth Menon ${ }^{3}$
}

\author{
${ }^{1}$ Aquaculture Pathology Laboratory, Department of Veterinary Science and Microbiology, University of Arizona, Tucson, \\ Arizona 85721, USA \\ ${ }^{2}$ Texas Veterinary Medical Diagnostic Laboratory, 1 Sippel Rd., Drawer 3040, College Station, Texas 77843, USA \\ ${ }^{3}$ Rajiv Gandhi Centre for Aquaculture (Domestication of Tiger Shrimp Project), Kodiaghat, Burmanala PO, Garacharma via, \\ South Andaman 744105, Andaman \& Nicobar Islands, India
}

\begin{abstract}
Shrimp (Penaeus monodon and P. vannamei) specimens were submitted to the University of Arizona's Aquaculture Pathology Laboratory (UAZAPL) and to the Texas Veterinary Medical Diagnostic Laboratory (TVMDL) in 2007 and 2008 from shrimp-rearing facilities in India and Indonesia for histological testing. These were found to present prominent golden to greenish-brown needleand plate-like birefringent crystals within multifocal hemocytic granulomas in the antennal gland tubules and peritubular hemal sinuses. Their appearance was very similar to melamine-cyanuric acid-induced crystals previously described from cat and dog kidneys with melamine-associated renal failure (MARF). Significant chronic mortalities were reported from the affected $P$. vannamei farms in Indonesia, but were not observed in the affected P. monodon facility in India. Shrimp feed was suspected as the source of melamine due to the similarity of the shrimp antennal gland lesions to those present in MARF. 'Normal' and 'suspect' feed samples from the facilities in Indonesia and India were sent to regional laboratories for analysis. Melamine was detected in 2 of 4 feed samples from an affected Indonesian farm. Melamine was not detected in 'normal' feed from the Indian facility, but it was found in 2 'suspect' samples (Feeds A and B) at levels of 183.39 and 112.50 ppm, respectively. A bioassay of Feed A with $P$. vannamei at UAZAPL confirmed that the melamine-contaminated feed induced prominent granulomas in the antennal gland with the characteristic crystals within $10 \mathrm{~d}$ of the first feeding, experimentally confirming the direct relationship of melamine-adulterated feed to the unique pathology observed.
\end{abstract}

KEY WORDS: Melamine $\cdot$ Cyanuric acid $\cdot$ Penaeid shrimp $\cdot$ Histology $\cdot$ Penaeus vannamei $\cdot$ Penaeus monodon · Bioassay

Resale or republication not permitted without written consent of the publisher

\section{INTRODUCTION}

Melamine adulteration of human and companion animal foods has been a prominent and ongoing story in the news since early 2007 when its use in pet-food formulations was linked to illness and death of thousands of dogs and cats in the USA due to melamineassociated renal failure (MARF) (Brown et al. 2007). This was followed by headlines in 2008 of renal failure and deaths of human infants in China, linked to the addition of melamine in infant formula and other processed milk products (Bradley 2009). Even earlier, renal failure in thousands of dogs and some cats associated with unknown toxic compounds in their feed was reported in Korea and Taiwan (Chiu 2004, Jeong et al. 2006; cited in Brown et al. 2007). Brown et al. (2007) noted that the lesions described from the dogs and cats in the 2004 to 2007 cases of renal disease from Asia were identical to those described in their 2007 paper. This indicated that the use of melamine (and related compounds, including cyanuric acid)-adulterated feed ingredients and feeds had been an ongoing practice for several years before these compounds were found to be the cause of renal failure. Melamine 
is $66.6 \%$ nitrogen and hence it has about 4.2 times more nitrogen than an equivalent amount of pure protein, which is about $16 \%$ nitrogen (Brubacher 2007). As a result, melamine and related compounds are added to low-protein feed ingredients or foods to falsely increase their apparent protein content when these ingredients are tested using traditional methods like the Kjeldahl assay, which estimates the protein content of foods based on their nitrogen content (Andersen et al. 2008).

In addition to melamine and related compounds being added to feed ingredients and other foods to increase their apparent protein content, melamine has also been used to improve the binding characteristics of certain feed ingredients and feeds in US agriculture and aquaculture. This attracted the attention of the US Food and Drug Administration (FDA), and in 2007 the FDA alerted livestock- and fish- and shrimp-feed manufacturers about a voluntary recall of US-made products used as binders in fish- and shrimp-feed production because feeds made with the binders were found to contain melamine and related compounds at levels of 233 and 465 ppm, respectively (Consumer Affairs 2007, USFDA 2007).

Reported in the present paper are observations from diagnostic submissions of shrimp specimens (black tiger shrimp Penaeus monodon and Pacific white shrimp $P$. vannamei) submitted to the University of Arizona's Aquaculture Pathology Laboratory (UAZAPL) and to the Texas Veterinary Medical Diagnostic Laboratory (TVMDL) from mid-2007 to late 2008 from India and Indonesia that were found to present prominent insoluble, golden to greenish-brown needle- and plate-like birefringent crystals within multifocal hemocytic granulomas in the lumens of the antennal gland tubules. These lesions were morphologically consistent with renal lesions in cats and dogs with MARF and were located within the kidney analog of shrimp, the antennal gland. Also reported here are the results of a bioassay in which the characteristic lesions were experimentally induced by feeding a shrimp feed that contained melamine to $P$. vannamei.

\section{MATERIALS AND METHODS}

Penaeus monodon from broodstock facility in India. Samples of subadult and adult black tiger shrimp $P$. monodon preserved in Davidson's alcohol, formalin, and acetic acid (AFA) (Bell \& Lightner 1988) were submitted in late 2007 to UAZAPL by the Rajiv Gandhi Centre for Aquaculture (RGCA) in India for routine health-status monitoring. Although no grossly apparent signs of disease were noted by the facility director at RGCA, prominent golden to greenish-brown crys- talline deposits within conspicuous granulomas (hereinafter called AG-Cry, for 'antennal gland crystals') of varying size were present in the antennal glands of nearly $100 \%$ of the $P$. monodon in the submission.

Penaeus vannamei from Indonesian farms. Identical AG-Cry lesions to those observed in P. monodon from India were also observed in Davidson's AFA-preserved specimens of juvenile $P$. vannamei submitted by an Indonesian farm to TVMDL in September and November 2007, and to UAZAPL in August 2008 by another Indonesian company. The affected shrimp farms included 2 semi-intensive farms and 1 intensive farm.

Feed samples and analysis. Due to the similarity of the granulomatous lesions containing conspicuous crystalline structures in the shrimp cases to those in dogs and cats with MARF (Brown et al. 2007), feed was suspected as the source of melamine responsible for the AG-Cry lesions in the submitted shrimp samples. For confirmation, both 'normal' and 'suspect' feed samples from the facility raising Penaeus monodon in India were sent to a regional laboratory for melamine analysis. Feed samples from one of the affected farms in Indonesia were also sent to a regional laboratory for melamine analysis.

From the RGCA broodstock facility, samples were taken of 'suspect' feeds (Feeds A and B from company ' $\mathrm{X}$ ' in Indonesia) that had been given to the affected populations of Penaeus monodon. For comparison, a 'normal' feed from another supplier (Feed C from company ' $\mathrm{Z}$ ' in Great Britain), which did not induce AG-Cry in P. monodon at RGCA, was also sent for analysis. These feed samples were submitted on January 2, 2008 to Interteck Testing Services (an accredited laboratory for melamine testing in Singapore) for melamine analysis, and the report with the results of the analyses was received at RGCA on January 4, 2008.

Bioassay with melamine-containing feed. Feed samples A and B from company X (Indonesia) were found to contain high levels of melamine. One kg of Feed A was shipped from RGCA to UAZAPL where it was used in a per os bioassay using juvenile specific pathogenfree (SPF) Penaeus vannamei (provided by the Oceanic Institute, Oahu, Hawaii) (Lightner et al. 2009, Moss \& Moss 2009) as the indicators for melamine-induced pathology. The bioassay system consisted of four $90 \mathrm{l}$ plastic tanks (numbered 1 to 4 ), each filled with artificial seawater (Forty Fathoms Biocrystal Marinemix, Environmental Enterprises International) adjusted to salinity 22. Each tank was fitted with a matured biological filter as described in White et al. (2002) and stocked with twelve $4.0 \mathrm{~g}$ average-weight juvenile $P$. vannamei. The bioassay was run at ambient temperature (25 to $28^{\circ} \mathrm{C}$ ). Tank 1 was the negative control tank and it received a control feed (Rangen's 35) with no melamine. All Rangen aquatic feeds manufactured after June 2007 
were melamine-free (J. Kinyon, Rangen Inc., Buhl, ID, pers. comm., April 27, 2009). The Rangen feed used for the control group in the present study was purchased on August 21, 2007 and was, therefore, melamine-free, while Tanks 2, 3, and 4 were replicate tanks that received Feed A with melamine. All feedings were at $6 \%$ of the tank biomass, divided into 2 equal feedings for 22 d. From Days 22 to 41, all 4 experimental tanks were fed the Rangen feed.

Shrimp were sampled from each of the 4 tanks for gross, wet-mount, and histological evaluation for AGCry after 0,10 , and $20 \mathrm{~d}$ of feeding the negative control and Feed A. A final sampling was conducted on Day 41, approximately $20 \mathrm{~d}$ after cessation of feeding with Feed A (see Table 1).

Microscopy and histological methods. Two (Day 10) or 4 (Day 20) shrimp from each experimental tank were chosen randomly and collected for analysis. From the Day 10 sample, the antennal gland region from 1 of the 2 specimens was excised and an unstained tissue squash was prepared. The remaining specimens from each tank and 4 specimens on Day 20 were preserved in Davidson's AFA for histological study. Upon termination (Day 41), all remaining shrimp were sampled and preserved in Davidson's AFA (see Table 1). Fixation and histological methods follow those outlined in Bell \& Lightner (1988).

\section{RESULTS}

\section{Case histories}

The samples of Penaeus monodon from the RGCA facility in India were submitted for routine disease surveillance in support of the development of SPF domesticated broodstock at the facility. No unusual gross signs or elevated mortalities were noted by the person submitting the samples. In contrast, the Indonesian biologists submitting the samples of $P$. vannamei for disease diagnosis from all 3 affected farms noted chronic mortalities in the affected stocks, with cumulative losses reaching 40 to $60 \%$ in some affected ponds.

\section{Histology of routine diagnostic specimens}

Samples of Penaeus monodon submitted for routine surveillance and diagnostic samples of diseased $P$. vannamei submitted to UAZAPL and TVMD from mid-2007 to late 2008 from aquaculture facilities in India and Indonesia presented prominent lesions with golden to greenish-brown needle- and plate-like birefringent crystals (AG-Cry) within multifocal hemocytic granulomas most often present in the lumens of the antennal gland tubules (Fig. 1a-d). Crystals occasionally occurred, with or without hemocytic infiltrates and nodule formation, in the peritubular hemal sinus among antennal gland tubules. The shape of the crystals ranged from blunt rectangular or plate-like forms (Fig. 1c,d) to thin elongated needle-like structures with some aligned in parallel bundles (Fig. 1a,b,d) while others displayed a partial or complete stellate pattern (Fig. 1d-f). As was reported by Brown et al. (2007) for melamine-cyanuric acid-induced MARF in dogs and cats, the AG-Cry in shrimp were birefringent with polarized light (Fig. 1d). Rare to infrequent scattered small hemocytic nodules lacking intralesional crystals were observed within the skeletal musculature of some of the more severely affected $P$. vannamei samples from Indonesia. However, it remains unclear whether these lesions were a consequence of melamine toxicity or due to some other etiologic agent.

Antennal gland lesion severity in the submitted clinical specimens and specimens from the feed bioassay was scored using a 0 to 4 grading scale adapted from Lightner (1996). With this system, Grade 0 (G0) means no AG-Cry lesions were observed, G0.5 means there were trace amounts of AG-Cry present, G1 indicates $<25 \%$ of the organ was affected, G2 indicates 25 to $50 \%$, G3 indicates 50 to $75 \%$, and G4 indicates $>75 \%$ of the organ was affected. The severity of AG-Cry lesions in clinical specimens of Penaeus monodon and $P$. vannamei from aquaculture facilities ranged from G0.5 to G4.

\section{Feed analysis results}

Results for the feeds from the RGCA facility sent to Interteck Testing Services showed feed samples A and B from company $\mathrm{X}$ (located in Indonesia) to contain 183.39 and 112.50 ppm melamine, respectively. Feed C (from company Z located in Great Britain) contained no melamine. Interteck Testing Services was requested to test for melamine only and not for melamine-related compounds like cyanuric acid.

The Indonesian company that submitted feed samples for melamine analysis reported the general findings without detailing the specific concentrations of melamine that were determined. Of 4 feeds tested, 2 were found to be 'melamine-free,' 1 demonstrated 'low' melamine levels, and 1 was 'heavily contaminated' with melamine.

\section{Feed bioassay}

AG-Cry lesions observed in specimens of Penaeus vannamei from the feed bioassay were identical to those presented in clinical specimens from the affected 

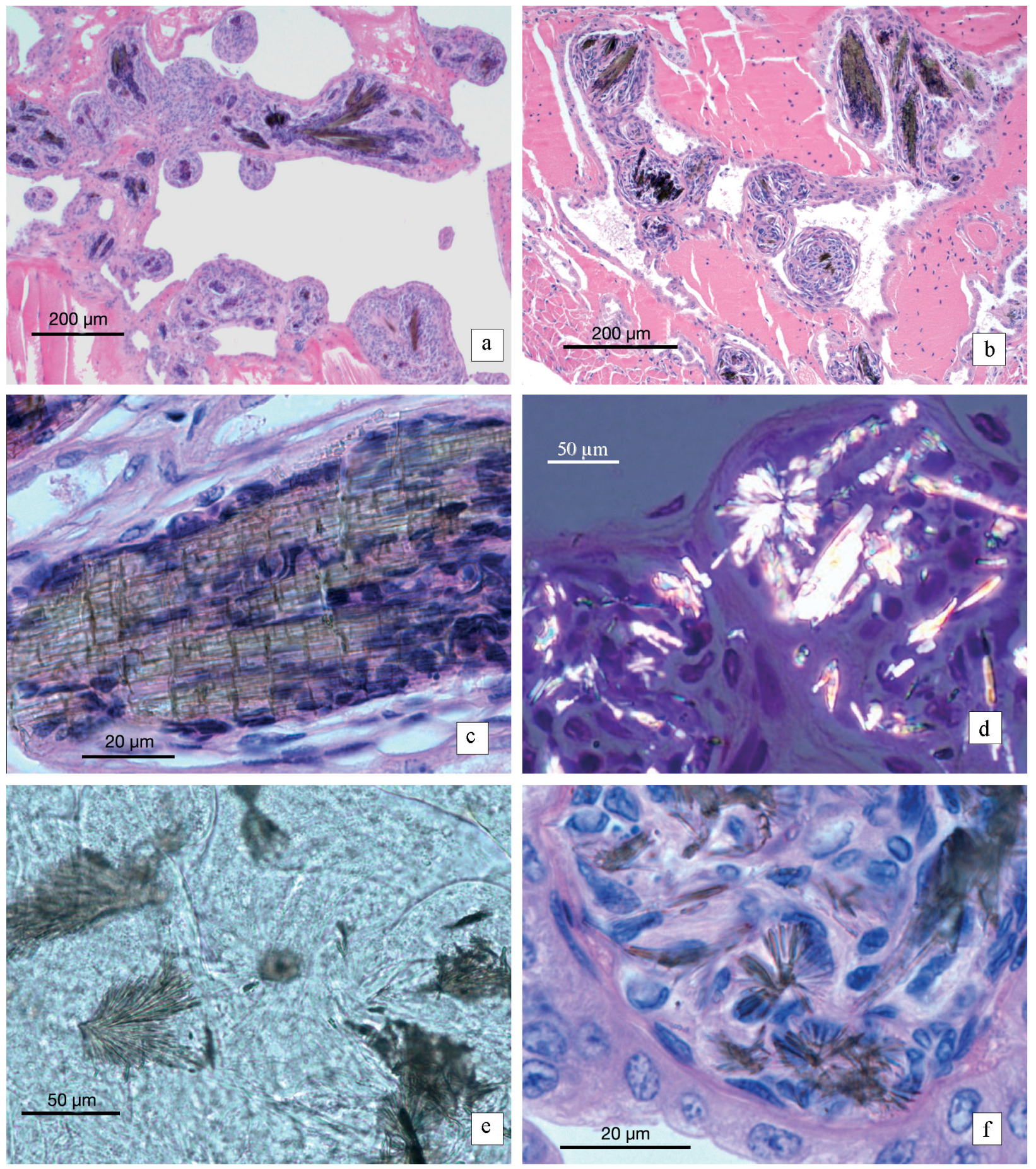

Fig. 1. Photomicrographs of melamine-induced granulomatosis in the antennal glands of (a to c) Penaeus monodon from an affected farm, (d) $P$. vannamei from an affected farm, and (e,f) $P$. vannamei fed Feed A (containing 183.39 ppm melamine) for 10 d. (a) Histological section of an antennal gland showing multiple granulomas that have formed around crystalline deposits of melamine-cyanurate. H\&E stain. (b) Antennal gland tubules with every tubule in the field containing a granuloma formed around crystals of melamine-cyanurate. (c) A golden to greenish-brown crystal of melamine-cyanurate in an antennal gland granuloma, with some details of the structure of plate-like subunits that make up the often needle-like crystals. H\&E stain. (d) Polarized light illumination illustrating the birefringent nature of the melamine-cyanuric acid crystals in a section of antennal gland tubules. H\&E stain. (e) Unstained wet-mount of melamine-cyanurate crystals from a tissue squash containing antennal gland tubules. (f) Histological section of a developing granuloma forming in response to melamine cyanurate crystals in the antennal gland. H\&E stain 
farms and broodstock facility (Fig. 1e,f), and they showed similar severity grades. In the bioassay, the rate of development of AG-Cry lesions and severity grade correlated to the length of time that the experimental shrimp were given the melamine-tainted feed (Table 1). The AG-Cry lesions increased from low grade (G0.5 to G1) on Day 10 of feeding (illustrated in an unstained tissue squash of antennal gland in Fig. 1e and in a comparable histological section in Fig. 1f), to a moderate mean severity grade of G2.2 by Day 20 (Table 1). The prevalence of AG-Cry lesions was $100 \%$ on Day 10, $100 \%$ on Day 20, and $94.7 \%$ on Day 41 (the termination day of the bioassay) and approximately $20 \mathrm{~d}$ after the cessation of giving Feed A with melamine to the indicator shrimp.

\section{DISCUSSION}

Identical AG-Cry lesions were observed in specimens of adult Penaeus monodon submitted for routine health and disease surveillance testing, in farm-reared juvenile $P$. vannamei submitted for disease diagnosis, and in a bioassay with juvenile SPF $P$. vannamei fed a feed with 183.39 ppm melamine (Lightner et al. 2008). The histological appearance of these crystals in shrimp was very similar to melamine-cyanuric acid-induced crystals described from the kidneys of dogs and cats with MARF (Brown et al. 2007), including being birefringent with polarized light. The difference in the general shape between the AG-Cry occurring in the shrimps' antennal gland and those occurring in the kidneys of dogs and cats is likely due to the tissue space in which they formed. These lesions appear to be unique in penaeid shrimp and not previously associated with any known shrimp diseases. Hence, the

Table 1. Experimental design and AG-Cry lesion (antennal gland granulomas with melamine-cyanuric acid crystals) severity (mean [range] grade on a scale from G0 to G4) and prevalence (Prev.) in juvenile Penaeus vannamei fed melamine-free Rangen feed (control) or Feed A containing 183.39 ppm melamine

\begin{tabular}{|c|c|c|c|c|}
\hline \multirow{2}{*}{\multicolumn{2}{|c|}{$\begin{array}{l}\text { Sample Treatment } \\
\text { day }\end{array}$}} & \multirow{2}{*}{$\begin{array}{c}\text { No. } \\
\text { sampled }\end{array}$} & \multicolumn{2}{|c|}{ —AG-Cry lesion } \\
\hline & & & Severity & Prev. (\%) \\
\hline \multirow[t]{2}{*}{10} & Control feed & 1 & G0 (0) & 0 \\
\hline & Feed A & 3 & G0.5 (G0.5 to G1.0) & 100 \\
\hline \multirow[t]{2}{*}{20} & Control feed & 3 & G0 (0) & 0 \\
\hline & Feed A & 12 & G2.2 (G1.5 to G3.0) & 100 \\
\hline \multirow[t]{2}{*}{41} & Control feed & 8 & G0 (0) & 0 \\
\hline & $\begin{array}{l}\text { Feed A + } \\
\text { control feed }^{\mathrm{a}}\end{array}$ & 19 & G1.0 (G0.5 to G2.5) & 94.7 \\
\hline \multicolumn{5}{|c|}{$\begin{array}{l}\text { aOn Day } 22, \text { Feed A was discontinued and the shrimp } \\
\text { were fed the Rangen feed for the remainder }(\sim 20 \mathrm{~d}) \text { of the } \\
\text { study }\end{array}$} \\
\hline
\end{tabular}

characteristic lesions may be considered pathognomonic for melamine toxicity.

The levels of melamine detected in Feeds A and B are similar to those reported by Consumer Affairs (2007), where levels of 233 and 465 ppm of melamine and related compounds, respectively, were reported in fish and shrimp feeds. These levels varied according to how much melamine-containing binder was used in the feed formulations. Although only melamine analysis for Feeds A and B was requested from Interteck Testing Services, the clinical findings of melaminecyanuric acid crystals in the affected shrimp indicates that melamine, cyanuric acid, and related compounds were likely to be present in the shrimp feeds associated with the presentation of AG-Cry lesions in shrimp. In any case, melamine and cyanuric acid were typically found in the tissues of cats and dogs with MARF, suggesting that melamine, cyanuric acid, or both were common in adulterated feeds or feed ingredients (Brown et al. 2007, USDA 2007).

While no obvious signs of disease or significant mortalities were noted in the Penaeus monodon fed the melamine-contaminated feed for several weeks or in the $P$. vannamei in the $41 \mathrm{~d}$ bioassay with melaminecontaining feed, managers submitting the samples from Indonesian farms noted signs of disease and elevated mortalities in the ponds from which the diagnostic samples were submitted. While specific melamine levels in the suspect feeds from Indonesia were not provided by the affected company that had their feeds tested, the possibility exists that the feed being used at the farm, where shrimp presented gross signs of disease and reduced survival, contained higher levels of melamine than the feeds used at RGCA and in the feed bioassay. The higher severity grades (e.g. G4) of AGCry noted in some samples of $P$. vannamei from at least one of the affected Indonesian farm supports this speculation. It is our understanding that, upon receiving reports that their shrimp losses were a consequence of melamine toxicity, the Indonesian farmers advised other industry members of the situation and the melamine problem was quickly corrected. We were advised that the Indonesian Shrimp Farmers Association, in cooperation with the Indonesian Department of Fisheries, began screening shrimp feeds to certify those that were melamine-free and eliminate those that were not.

In a related study run by the FDA, catfish, trout, tilapia, salmon, and shrimp (species not specified) were fed varying quantities of melamine, cyanuric acid, and a combination of melamine and cyanuric acid (Andersen et al. 2008). The target doses were $400 \mathrm{mg} \mathrm{kg}^{-1}$ body weight of melamine or cyanuric acid, or a combined dose of $400 \mathrm{mg} \mathrm{kg}^{-1}$ melamine plus $400 \mathrm{mg} \mathrm{kg}^{-1}$ cyanuric acid (Andersen et al. 2008). 
The fish were dosed for $3 \mathrm{~d}$, then euthanized and examined for melamine tissue residues and crystal formation in the kidneys (Andersen et al. 2008). The shrimp were fed feed containing 50 or $100 \mathrm{mg} \mathrm{kg}^{-1}$ melamine for $14 \mathrm{~d}$ and then sampled for melamine analysis in edible tissue (Andersen et al. 2008). Melamine was found at levels of 41,217 , and $51 \mu \mathrm{g}$ $\mathrm{kg}^{-1}$ in shrimp fed the control, $50 \mathrm{mg} \mathrm{kg}^{-1}$, and $100 \mathrm{mg} \mathrm{kg}^{-1}$ feed, respectively (Andersen et al. 2008). In a subsequent analysis, the 'control' shrimp feed was confirmed to contain melamine at a concentration in excess of $100 \mathrm{mg} \mathrm{kg}^{-1}$ (Andersen et al. 2008). The shrimp in the Andersen et al. (2008) study were not examined for lesions or crystal formation.

Due to concerns about melamine-contaminated feeds used to feed animals, an interim safety and risk assessment was conducted by 5 US government agencies: the FDA and the Centers for Disease Control and Prevention (CDC) of the Department of Health and Human Services (HHS), the Environmental Protection Agency (EPA), US Customs and Border Protection (CBP) of the Department of Homeland Security (DHS), and the Food Safety and Inspection Service (FSIS) of the USDA. The risk assessment concluded that the consumption of pork, chicken, domestic fish, and eggs from animals inadvertently fed feed contaminated with melamine and its analogs is very unlikely to pose a human health risk (USDA 2007). The findings from the present shrimp study, in which melamine-associated pathology was limited to the presence of insoluble crystals of salts of melaminecyanuric acid in the antennal gland, and the Andersen et al. (2008) study in which a maximum of $217 \mu \mathrm{g}$ $\mathrm{kg}^{-1}$ residue of melamine was found in edible shrimp tissue, are consistent with the USDA (2007) risk assessment. This suggests that the tail meat of melamine-exposed shrimp is also unlikely to pose a human health risk.

The findings of the present study, when considered with other published information, document that some shrimp feeds manufactured in Indonesia and the USA have contained one or more ingredients adulterated with melamine and related compounds. Testing of such feeds with traditional methods for protein content using the Kjeldahl method will not identify the presence of melamine and related compounds as contaminants. Hence, the routine testing of feeds and/or feed ingredients specifically for melamine and related compounds, coupled with passive surveillance in which unusual episodes of disease in shrimp farms are investigated using routine histopathology, may be appropriate measures to monitor for melamine-adulterated feeds.
Acknowledgements. Support for this work was provided by grants or contracts from the United States Marine Shrimp Farming Program, Cooperative State Research, Education and Extension Service, USDA, the National Fisheries Institute, and the Rajiv Gandhi Centre for Aquaculture (Marine Products Development Authority), India.

\section{LITERATURE CITED}

Andersen WC, Turnipseed SB, Karbiwnk CM, Clark SB and others (2008) Determination and confirmation of melamine residues in catfish, trout, tilapia, salmon, and shrimp by liquid chromatography with tandem mass spectrometry. J Agric Food Chem 56:4340-4347

Bell TA, Lightner DV (1988) A handbook of normal shrimp histology. Spec Publ 1. World Aquaculture Society, Baton Rouge, LA

Bradley D (2009) Melamine milk update. www.sciencebase. com/science-blog/melamine-milk-update.html (acccessed Feb 2, 2009)

Brown CA, Jeong KS, Poppenga RH, Puschner B and others (2007) Outbreaks of renal failure associated with melamine and cyanuric acid in dogs and cats in 2004 and 2007. J Vet Diagn Invest 19:525-531

Brubacher L (2007) Pets and melamine. Chem 13 News 346:1 \& 3. University of Waterloo, Waterloo, ON. www. chem13news.uwaterloo.ca/issues/349/349_Sept_07.html (accessed Apr 22, 2009)

Chiu T (2004) Pet food manufacturer sued by dog owners. Taipei Times, July 2 2004, p 2

Consumer Affairs (2007) Two U.S. companies recall melamine-tainted feed. www.consumeraffairs.com/news04/ 2007/05/melamine_us.html (accessed Jan 15, 2008)

Jeong WI, Do SH, Jeong DH, Chung JY and others (2007) Canine renal failure syndrome in three dogs. J Vet Sci 7:299-301

Lightner DV (ed) (1996) A handbook of shrimp pathology and diagnostic procedures for diseases of cultured penaeid shrimp. World Aquaculture Society, Baton Rouge, LA

Lightner DV, Pantoja CP, Redman RM, Pozoth J (2008) Feedrelated melamine risk minimal to shrimp, humans. Global Aquacult Advocate 11:30-31

Lightner DV, Redman RM, Arce S, Moss SM (2009) Specific pathogen-free shrimp stocks in shrimp farming facilities as a novel method for disease control in crustaceans. In: Shumway S, Rodrick G (eds) Shellfish safety and quality. Woodhead Publishing, Cambridge, p 384-424

Moss SM, Moss DR (2009) Selective breeding of penaeid shrimp. In: Shumway S, Rodrick G (eds) Shellfish safety and quality. Woodhead Publishing, Cambridge, p 425-452

USDA (US Department of Agriculture) (2007) Interim melamine and analogues safety/risk assessment. USDA fact sheet. News release 0129.07. www.usda.gov/2007/05/ 0129.xml (accessed Aug 21, 2009)

USFDA (US Food and Drug Administration) (2007) Tembec and Uniscope voluntary recall feed ingredients. FDA asks feed manufacturers to avoid ingredients containing melamine. FDA news release P07-94. www.fda.gov/ NewsEvents/Newsroom/PressAnnouncements/2007/ ucm108925.htm (accessed Aug 21, 2009)

> White BL, Schofield PJ, Poulos BT, Lightner DV (2002) A laboratory challenge method for estimating Taura syndrome virus resistance in selected lines of Pacific white shrimp Litopenaeus vannamei. J World Aquacult Soc 33:341-348 